\title{
Lymph node involvement in advanced gastroesophageal junction adenocarcinoma
}

\author{
Corrado Pedrazzani, MD, a Giovanni de Manzoni, MD, ${ }^{\mathrm{b}}$ Daniele Marrelli, MD, ${ }^{\text {a }}$ Simone Giacopuzzi, MD, ${ }^{\mathrm{b}}$ \\ Giovanni Corso, MD, ${ }^{a}$ Anna Maria Minicozzi, MD, ${ }^{b}$ Bernardino Rampone, MD, and Franco Roviello, MDa
}

Objective: The prognosis of gastroesophageal junction adenocarcinoma is unquestionably related to the extent of nodal involvement; nonetheless, few studies deal with the pattern of lymph node spread and specifically analyze the prognostic value of the site of metastasis. The present study was aimed at evaluating these key aspects in advanced gastroesophageal junction adenocarcinoma.

Methods: Of 219 patients consecutively operated on for gastroesophageal junction adenocarcinoma at the Department of General Surgery and Surgical Oncology, University of Siena, and at the Department of General Surgery, University of Verona, 143 pT2-4 tumors not submitted to prior chemoradiation were analyzed according to the Japanese Gastric Cancer Association pN staging system.

Results: The majority of patients were given diagnoses of nodal metastases (77.6\%). The mean number $(P=.076)$ and the percentage of patients with $\mathrm{pN}^{+}$disease $(P=$ .022) progressively increased from Siewert type I to type III tumors. Abdominal nodes were involved in all but 1 of the patients with $\mathrm{pN}^{+}$disease; conversely, nodal metastases into the chest were $46.2 \%$ for type I, $29.5 \%$ for type II, and $9.3 \%$ for type III tumors. Survival analysis showed virtually no chance of recovery for patients with more than 6 metastatic nodes or lymph nodes located beyond the first tier.

Conclusions: In advanced gastroesophageal junction adenocarcinoma, the high frequency of nodal metastases and the related unfavorable long-term outcome achieved by means of surgical intervention alone are indicative of the need for aggressive multimodal treatment along with surgical intervention to improve longterm results.

From the Department of Human Pathology and Oncology, Unit of Surgical Oncology, ${ }^{a}$ University of Siena, Siena, Italy; and the Department of General Surgery, ${ }^{\mathrm{b}}$ University of Verona, Verona, Italy.

Supported by a grant from the CNR-MIUR.

Received for publication Sept 18, 2006; revisions received Jan 24, 2007; accepted for publication March 8, 2007.

Address for reprints: Giovanni de Manzoni, MD, Via Franchetti 6, 57100 Verona, Italy (E-mail: gdemanzon@mail.univr.it).

J Thorac Cardiovasc Surg 2007;134:378-85 $0022-5223 / \$ 32.00$

Copyright $\odot 2007$ by The American Association for Thoracic Surgery

doi:10.1016/j.jtcvs.2007.03.034
A denocarcinoma of the gastroesophageal junction (GEJ) remains a neoplasia of great interest in view of the remarkable increase of incidence observed during the last decades ${ }^{1,2}$ and of the unfavorable long-term results achieved by means of surgical intervention alone, even after extended resections. ${ }^{3-5}$ The prognosis of GEJ adenocarcinoma is unquestionably related to the extent of nodal involvement, ${ }^{6,7}$ which is complicated by the regional lymphatic drainage of the tumor evenly above and below the diaphragm. ${ }^{8,9}$

The Japanese literature and some dedicated Western centers extensively investigated the pattern of lymph node spread in stomach cancer to characterize the pattern of dissemination, to define the appropriate extent of nodal dissection, and to evaluate the related prognostic significance. ${ }^{10-12}$

The mode of diffusion of GEJ adenocarcinoma is less known, and the pattern of lymph node spread and its prognostic significance have not yet been investigated in this tumor. The present study was aimed at considering these key aspects in GEJ adenocarcinoma. 


\section{Abbreviations and Acronyms \\ GEJ = gastroesophageal junction \\ JGCA = Japanese Gastric Cancer Association}

\section{Materials and Methods}

\section{Inclusion Criteria and Study Population}

GEJ adenocarcinoma was defined according to the Siewert classification. ${ }^{13}$ The most important inclusion criteria were histologic diagnosis of adenocarcinoma; no preoperative chemotherapy, radiotherapy, or both; locally advanced tumor (pT2, pT3, and pT4); macroscopic curative resection (R0-R1); no systemic metastasis; no history of secondary malignancy; and possibility of follow-up with a minimum follow-up period of 18 months. Informed consent was obtained from all the patients, and the study was approved by the local ethics committee.

Two hundred nineteen patients affected by GEJ adenocarcinoma underwent resection at the Department of General Surgery and Surgical Oncology, University of Siena, between January 1995 and June 2004 and at the Department of General Surgery, University of Verona, between January 1988 and June 2004. Among these, 76 patients did not match the inclusion criteria and were hence excluded from the analysis. In particular, 39 patients underwent preoperative chemoradiotherapy (type I, 17 patients; type II, 22 patients), ${ }^{14} 19$ patients underwent macroscopic noncu- rative (R2) surgical intervention (type II, 10 patients; type III, 9 patients), and a pT1 tumor was diagnosed in 18 patients (type I, 7 patients; type II, 8 patients; type III, 3 patients).

Clinical, histopathologic, and follow-up data of the 143 patients under study were prospectively collected and presented in Table 1. The median age of the cohort was 68 years (range, 27-90 years), with a male/female ratio of 4.5 to 1 .

\section{Staging Work-up}

Preoperative work-up included a barium swallow, esophagogastroscopy with biopsy, and computed tomography of the chest and abdomen in every case. Endoscopic ultrasonography was performed in 79 patients, whereas neither thoracoscopy nor laparoscopy was used in this series of patients for evaluation of tumor resectability or staging.

\section{Surgical Intervention}

Surgical resection and mode of reconstruction have been previously described in detail. ${ }^{3}$ Briefly, the standard procedure for type I tumors was a right thoracotomy with a subtotal esophagectomy above the azygos vein with proximal gastric resection. The procedure of choice for type III tumors was a total gastrectomy with transhiatal resection of the distal esophagus. A transthoracic approach was necessary in 2 cases. Type II tumors were treated with subtotal esophagectomy, as in type I cancers, or with total gastrectomy with transhiatal or transthoracic resection of the distal

TABLE 1. Main clinicopathologic characteristics according to Siewert classification for the 143 patients under study*

\begin{tabular}{|c|c|c|c|c|}
\hline \multirow[b]{2}{*}{ Variable } & \multicolumn{3}{|c|}{ Siewert type } & \multirow[b]{2}{*}{$P$ value } \\
\hline & Type I (n = 20) & Type II $(n=62)$ & Type III (n= 61) & \\
\hline Age (y) & & & & .937 \\
\hline Median (range) & $68(27-90)$ & $67(27-90)$ & $68(36-82)$ & \\
\hline Sex & & & & 137 \\
\hline Male $(n=117)$ & $19(95)$ & $47(75.8)$ & $51(83.6)$ & \\
\hline Female $(n=26)$ & $1(5)$ & $15(24.2)$ & $10(16.4)$ & \\
\hline Lauren type & & & & .117 \\
\hline Intestinal ( $n=102)$ & $16(80)$ & $48(77.4)$ & $38(62.3)$ & \\
\hline Nonintestinal $(n=41)$ & $4(20)$ & $14(22.6)$ & $23(37.7)$ & \\
\hline Depth of invasion (pT) & & & & .007 \\
\hline $\mathrm{pT} 2(\mathrm{n}=62)$ & $9(45)$ & $32(51.6)$ & $21(34.4)$ & \\
\hline pT3 (n = 69) & $11(55)$ & $29(46.8)$ & $29(47.5)$ & \\
\hline pT4 $(n=12) \dagger$ & - & $1(1.6)$ & $11(18)$ & \\
\hline Nodal involvement (pN) & & & & .022 \\
\hline $\mathrm{pNO}(\mathrm{n}=32)$ & $7(35)$ & $18(29)$ & $7(11.5)$ & \\
\hline $\mathrm{pN}+(\mathrm{n}=111)$ & $13(65)$ & $44(71)$ & $54(88.5)$ & \\
\hline No. of positive nodes & & & & .036 \\
\hline $0(\mathrm{n}=32)$ & $7(35)$ & $18(29)$ & $7(11.5)$ & \\
\hline $1-6(n=53)$ & $9(45)$ & $21(33.9)$ & $23(37.7)$ & \\
\hline$>6(\mathrm{n}=58)$ & $4(20)$ & $23(37.1)$ & $31(50.8)$ & \\
\hline Mean $( \pm S D)$ no. of positive nodes & $4.2(7.4)$ & $7.5(10.3)$ & $10.4(13.1)$ & .076 \\
\hline $\mathrm{R}$ category & & & & .474 \\
\hline $\mathrm{RO}(\mathrm{n}=129)$ & $19(95)$ & $57(91.9)$ & $53(86.9)$ & \\
\hline R1 ( $n=14) \ddagger$ & $1(5)$ & $5(8.1)$ & $8(13.1)$ & \\
\hline
\end{tabular}

$S D$, Standard deviation. *Numbers in parentheses are percentages. †R0 resection was achieved in 10 (83.3\%) of 12 patients with pT4 disease. $¥$ Microscopic residual disease was at the proximal resection margin in 9 patients, at the distal resection margin in 1 patient, and in peritoneal washing in 4 patients. 
esophagus, as in type III tumors; the type of resection was chosen to obtain clear proximal and distal margins and adequate lymphadenectomy. After subtotal esophagectomy, reconstruction was performed with a gastric tube, whereas a jejunal Roux-en-Y reconstruction was performed after total gastrectomy.

Lymph node dissection was classified according to the Japanese Gastric Cancer Association (JGCA) rules: D1 lymphadenectomy (resection of perigastric nodes in positions 1-4s), D2 lymphadenectomy (resection of nodes in positions 1-11), and D3 lymphadenectomy (resection extended to the nodes in positions 12-16). ${ }^{15}$ The preferred lymph node dissection was a standard mediastinal (including paraesophageal, tracheal bifurcation, right bronchial, posterior mediastinal, and diaphragmatic nodes) and D2 abdominal lymphadenectomy for type I tumors and D2-D3 abdominal lymphadenectomy added to nodes of the lower posterior mediastinum for type II and III tumors. Lymphadenectomy at the splenic hilum was limited to patients with enlarged nodes or tumors reaching the gastric fundus, and it was achieved by means of pancreas-preserving splenectomy. D1 dissection was reserved for high-risk patients.

\section{Pathologic Staging and Assignment to JGCA Nodal Station}

Considering the depth of tumor invasion (pT), American Joint Committee on Cancer and International Union Against Cancer rules for esophageal cancer were adopted in Siewert type I tumors, whereas those for gastric cancer were used in Siewert type II and III tumors. ${ }^{16}$ Regarding nodal staging $(\mathrm{pN})$, both the number and site of nodal metastasis were evaluated in each case. The numberbased classification was derived from the American Joint Committee on Cancer and International Union Against Cancer classification for gastric cancer, ${ }^{16}$ and 3 classes were considered: no positive nodes, 1 to 6 positive nodes, and greater than 6 positive nodes. The site-based classification adhered to the criteria stated by the JGCA. ${ }^{15}$ Perivisceral lymph nodes were dissected from the excised specimen by the surgeon immediately after resection, assigned to the appropriate station according to the JGCA classification, and sent for histologic examination. The second- and third-tier nodes were subdivided by the surgeon himself during lymphadenectomy, as described in a previous study, ${ }^{17}$ to avoid errors caused by difficulties in assigning nodes to the correct lymph node station after en bloc resection.

According to the JGCA, stations 1, 2, 3, and 4s were regarded as first-tier nodes; inversely, other lymph nodes were termed non-first tier. Additionally, paraesophageal nodes of the lower third (station 110) were considered as first-tier nodes in type I tumors.

The histologic classification followed the criteria of Lauren, and mixed-type tumors were considered together with the diffuse type (nonintestinal type).

\section{Follow-up}

After discharge from the hospital, all patients were followed up after 4 months and subsequently at 6-month intervals until their death or the time of study (December 2005). None of the patients was lost to follow-up. The median follow-up period for surviving patients was 46.5 months (range, 18.2-208.1 months).

\section{Statistical Analysis}

The $\chi^{2}$ test was used for categoric data and the analysis of variance test for continuous variables was used to evaluate the significance of differences among Siewert types.

Survival curves were estimated by using the Kaplan-Meier method and compared by using the log-rank test. Multivariate analysis was performed with the Cox regression model to evaluate the independent prognostic value of lymph node involvement. Relative risks in relation to the site and number of nodal metastases were considered separately and derived by controlling for age, sex, Siewert type, Lauren type, pT, and R category. Deaths from causes other than GEJ adenocarcinoma were considered censored observations at the time of death. Patients who died during the postoperative period were computed in survival analysis. Analyses were performed with the Statistical Product and Service Solutions (SPSS 12.0 for Windows XP; SPSS, Inc, Chicago, Ill).

\section{Results}

In the series of 143 patients, a total of 5357 lymph nodes was retrieved and analyzed, with a mean number \pm SD per patient of $37.5 \pm 20.3$. The mean \pm SD number of dissected nodes was $23.4 \pm 10.8$ for type I, $37.3 \pm 19.9$ for type II, and $42.3 \pm 21.1$ for type III tumors $(P<.001)$. A mean \pm SD of $18.8 \pm 10.1$ nodes was removed by means of D1 lymphadenectomy, $35.2 \pm 17.1$ by means of D2 lymphadenectomy, and $47.8 \pm 20.5$ by means of D3 lymphadenectomy $(P<.001)$.

\section{Incidence of Nodal Metastases}

Metastases were diagnosed in 1186 lymph nodes in 111 (77.6\%) patients for a mean $\pm \mathrm{SD}$ of $8.3 \pm 11.4$. The mean \pm SD number $(P=.076)$ and the percentage of patients with $\mathrm{pN}^{+}$disease $(P=.022)$ progressively increased from type I to type III tumors (Table 1). The incidence of nodal metastases, as well as the mean number of involved nodes $(P=.042)$, significantly correlated with the depth of tumor invasion (pT). Lesions with invasion limited to the visceral wall (pT2) had a $61.3 \%$ incidence of $\mathrm{pN}^{+}$disease; it was $88.4 \%$ for pT3 tumors, whereas all pT4 lesions showed nodal metastases $(P<.001)$. More than 6 metastatic nodes were present in $18(29.0 \%)$ patients with pT2 disease, in 31 $(44.9 \%)$ patients with pT3 disease, and in $9(75 \%)$ patients with pT4 disease $(P<.001)$.

\section{Distribution of Nodal Metastases}

The conformity and pertinence of lymphadenectomy evaluated according to the total/mean number of retrieved nodes for each JGCA station and to the percentage of patients in which each single JGCA station had been retrieved are reported in Table 2. Figure 1 correlates the distribution of nodal metastases with the location of the tumor according to Siewert classification.

The site and level of nodal metastases for the 3 Siewert types in the 111 node-positive patients is reported in 
TABLE 2. Conformity and pertinence of lymphadenectomy according to Siewert classification for the 143 patients under study*

\begin{tabular}{|c|c|c|c|c|}
\hline & & & an no. of retriev & \\
\hline & node station (JGCA) & Type I & Type II & Type III \\
\hline 1 & Right paracardial & 49/2.6 (95) & $257 / 4.4(95.2)$ & 190/3.7 (85.2) \\
\hline 2 & Left paracardial & $37 / 2(95)$ & $158 / 2.7(93.5)$ & $83 / 1.8(77)$ \\
\hline 3 & Lesser curvature & $101 / 5.1(100)$ & $413 / 6.8(98.4)$ & $533 / 8.7(100)$ \\
\hline $4 s$ & Greater curvature & $10 / 0.8(60)$ & $101 / 1.9(83.9)$ & $155 / 3.4(75.4)$ \\
\hline $4 d$ & Right gastroepiploic artery & $2 / 1(10)$ & $123 / 2.9(67.7)$ & $168 / 3.7(75.4)$ \\
\hline 5 & Suprapyloric & - & $44 / 1.1(67.7)$ & $26 / 0.6(72.1)$ \\
\hline 6 & Infrapyloric & - & $148 / 3.7(64.5)$ & $168 / 3.6(77)$ \\
\hline 7 & Left gastric artery & $30 / 2(75)$ & $160 / 3.0(87.1)$ & $136 / 2.8(80.3)$ \\
\hline 8 & Common hepatic artery & $23 / 2.1(55)$ & $180 / 4.0(72.1)$ & $144 / 4.2(55.7)$ \\
\hline 9 & Celiac trunk & $29 / 2.4(60)$ & $117 / 2.9(64.5)$ & $129 / 3.7(57.4)$ \\
\hline 10 & Splenic hilum & $2(5)$ & $37 / 1.8(33.9)$ & $78 / 2.8(45.9)$ \\
\hline 11 & Splenic artery & $21 / 1.9(55)$ & $72 / 2.0(58.1)$ & $69 / 2.3(49.2)$ \\
\hline 12 & Hepatoduodenal ligament & $8 / 2(20)$ & $66 / 2.8(38.7)$ & $93 / 3.9(39.3)$ \\
\hline 16 & Para-aortic & - & $140 / 5.4(41.9)$ & $174 / 6.4(44.3)$ \\
\hline 107 & Subcarinal & $32 / 2.3(70)$ & $38 / 2.1(29)$ & $8 / 4(3.3)$ \\
\hline 108 & Paraesophageal middle third & $22 / 1.5(75)$ & $22 / 1.7(21)$ & $4 / 2(3.3)$ \\
\hline 110 & Paraesophageal lower third & $39 / 2.3(85)$ & $65 / 1.9(54.8)$ & $40 / 2.1(31.1)$ \\
\hline 111 & Supradiaphragmatic & $22 / 1.6(70)$ & $40 / 1.6(40.3)$ & $40 / 1.8(35.5)$ \\
\hline 112 & Posterior mediastinal & $34 / 2.1(80)$ & $62 / 2.2(45.1)$ & $46 / 2.1(35.5)$ \\
\hline
\end{tabular}

JGCA, Japanese Gastric Cancer Association. *Numbers in parentheses represent the percentage of patients in which each single Japanese Gastric Cancer Association station has been retrieved.

Table 3. All but 1 of the patients with $\mathrm{pN}^{+}$disease showed an involvement of abdominal nodes (99.1\%); conversely, nodal metastases into the chest were diagnosed in $6(46.2 \%)$ type I, $13(29.5 \%)$ type II, and 5 $(9.3 \%)$ type III tumors.

\section{Survival Analysis}

Table 4 reports survivals according to the main clinicopathologic characteristics of the cohort under study. It is noteworthy that virtually no chance of recovery was observed for patients with more than 6 metastatic nodes $(P<.001)$.

Survival according to the presence of nodal metastasis is reported for each JGCA nodal station in Table 5. Remarkably, among patients with $\mathrm{pN}^{+}$disease, long-term survival was restricted to a small proportion of patients with involvement limited to the first-tier perigastric nodes. One patient with deposits in a single lymph node located at the left gastric artery (station 7) survived beyond 60 months.

Multivariate analysis confirmed the independent prognostic value of nodal involvement, both considering the number (relative risk with respect to pN0, 2.20 [95\% CI, $1.10-4.39$ with $1-6$ nodes] and 5.00 [95\% CI, 2.47-10.12 with $>6$ nodes]; $P<.001$ ) and site (relative risk with respect to $\mathrm{pN} 0,1.86$ [95\% CI, $0.90-3.84$ with first-tier nodes] and 4.13 [95\% CI, 2.11-8.12 with non-first-tier nodes]; $P<.001$ ) of nodal metastases.

\section{Discussion}

The major findings of the present study are as follows: (1) nodal involvement is confirmed as a common event in advanced GEJ adenocarcinoma; (2) the pattern of lymph node spread herein observed was somewhat different among the 3 Siewert types; (3) abdominal nodes were involved in almost all patients with $\mathrm{pN}^{+}$disease; and (4) long-term survival was mostly limited to patients with pNO disease and to patients with fewer than 7 metastatic nodes located within the first tier.

Reported data about the nodal spread of GEJ adenocarcinoma are scanty and hard to compare because of a lack of an overall consensus on the definition, staging, and treatment of this tumor. ${ }^{9,13,18,19}$

Surgical treatment is considered the mainstay of therapy, and its founding oncologic principle is focused on the completeness of tumor removal (R0 resection), which has proved to be essential for achieving long-term survival. ${ }^{3,20,21}$ Prognosis of GEJ adenocarcinoma is poor because advanced depth of invasion of the visceral wall and lymph node involvement are usually present at onset ${ }^{3,18,22}$; accordingly, more than three fourths of our patients were diagnosed with nodal deposits. As is well established, lymph node involvement proved to be a significant predictor of survival ${ }^{6,7,23}$ and a major determinant of locoregional recurrence. ${ }^{24,25}$ For these reasons, lymphadenectomy is considered key in the surgical 


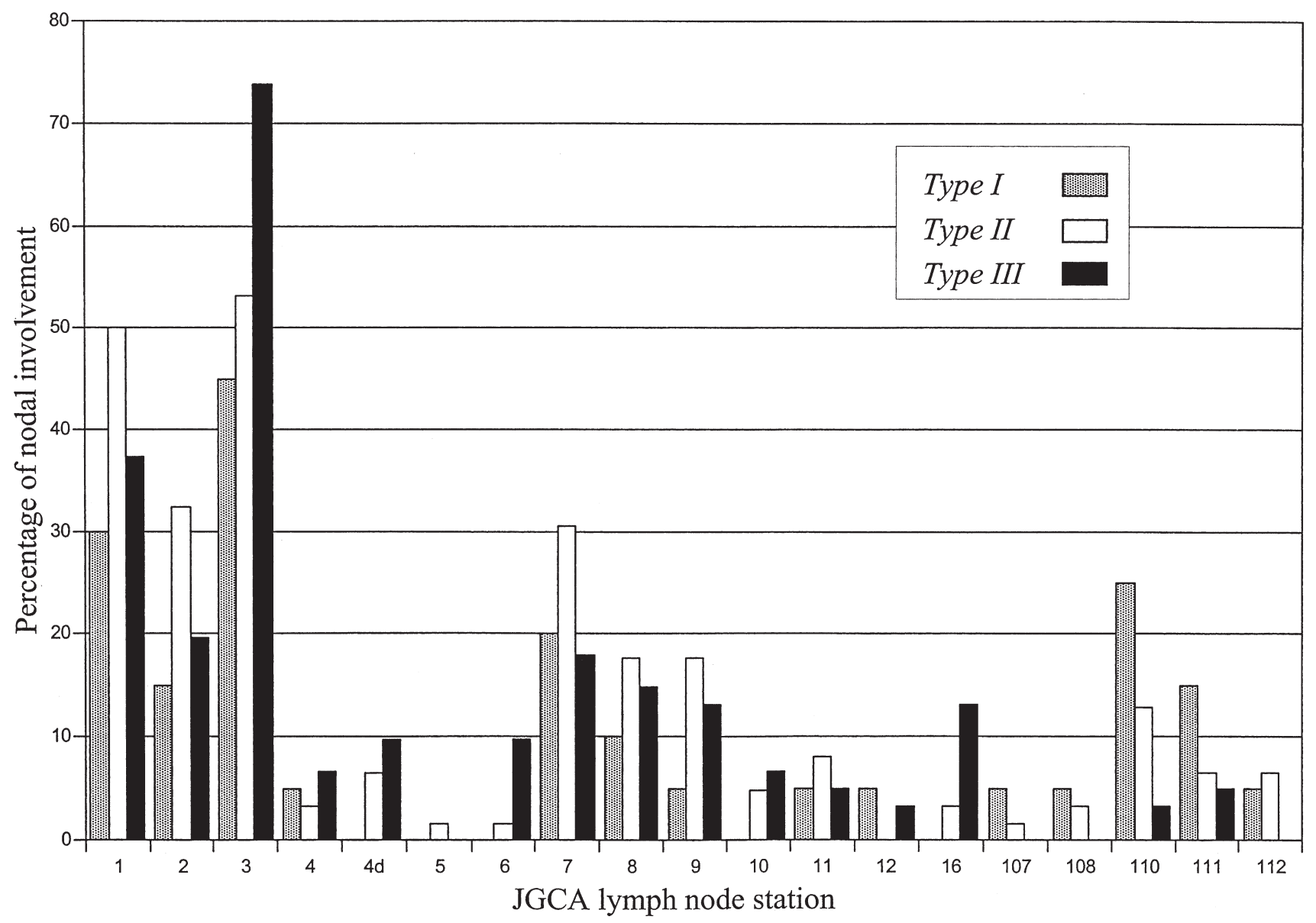

Figure 1. Percentage of nodal involvement to each Japanese Gastric Cancer Association (JGCA) lymph node station according to the tumor location (Siewert type I, type II, and type III) for the $\mathbf{1 4 3}$ patients under study.

treatment of this tumor. Nonetheless, great controversy continues over the optimal extent of lymph node dissection in the absence of prospective randomized trials demonstrating a clear benefit of extended versus limited lymphadenecto-

TABLE 3. Location of nodal metastases according to Siewert classification for the 111 patients with $\mathrm{pN}^{+}$disease*

\begin{tabular}{|c|c|c|c|}
\hline & \multicolumn{3}{|c|}{ Siewert type } \\
\hline & $\begin{array}{c}\text { Type I } \\
(\mathrm{n}=13)\end{array}$ & $\begin{array}{c}\text { Type II } \\
(\mathrm{n}=44)\end{array}$ & $\begin{array}{r}\text { Type III } \\
(\mathrm{n}=54)\end{array}$ \\
\hline \multicolumn{4}{|l|}{ Level of nodal metastasis } \\
\hline First tier $(\mathrm{n}=43)$ & $6(46.2)$ & $15(34.1)$ & $22(40.7)$ \\
\hline Non-first tier (n = 68) & $7(53.8)$ & $29(65.9)$ & $32(59.3)$ \\
\hline \multicolumn{4}{|l|}{ Site of nodal metastasis } \\
\hline Abdomen $(\mathrm{n}=87)$ & $7(53.8)$ & $31(70.5)$ & $49(90.7)$ \\
\hline $\begin{array}{l}\text { Abdomen and chest } \\
(\mathrm{n}=23)\end{array}$ & $6(46.2)$ & $13(29.5)$ & $4(7.4)$ \\
\hline Chest $(\mathrm{n}=1)$ & - & - & $1(1.9)$ \\
\hline
\end{tabular}

*Numbers in parentheses are percentages. mies. ${ }^{26-28}$ In addition, understanding the mode in which GEJ adenocarcinoma spreads to lymph nodes and the related prognostic significance is helpful in defining the appropriate extent of nodal dissection and in tailoring the most appropriate treatment for this tumor.

As already seen in radioisotope lymphography ${ }^{29}$ and reported in clinical studies, ${ }^{8,9,30,31}$ lymphatic pathways are mainly directed toward the abdomen. In fact, abdominal tiers were involved in virtually all patients with $\mathrm{pN}^{+}$disease, and metastases confined to abdominal nodes were $90.7 \%, 70.5 \%$, and $53.8 \%$ in type III, type II, and type I tumors, respectively. Conversely, the overall rate of nodal metastases into the chest were $46.2 \%$ for type I, $29.5 \%$ for type II, and $9.3 \%$ for type III tumors, and isolated metastases to mediastinal nodes were rarely observed (1 patient).

In Siewert type I tumors paraesophageal nodes of the lower third (station 110) were infiltrated in 1 of 4 patients, whereas metastases were less frequently diagnosed in type II (12.9\%) and type III (3.3\%) tumors. Dresner and colleagues ${ }^{8}$ reported double that rate of paraesophageal node 
TABLE 4. Survival according to main clinicopathologic characteristics for the 143 patients under study

\begin{tabular}{|c|c|c|c|c|}
\hline $\begin{array}{l}\text { Lymph node station } \\
\text { (JGCA) }\end{array}$ & $\begin{array}{l}\text { No. of patients } \\
\text { (no. alive) }\end{array}$ & $\begin{array}{l}\text { Median } \\
\text { survival* }\end{array}$ & $\begin{array}{c}\text { 5-y } \\
\text { survivalt }\end{array}$ & $\begin{array}{c}P \\
\text { valuef }\end{array}$ \\
\hline Age & & & & .200 \\
\hline$<$ Median & $71(25)$ & 21.4 & 27.7 & \\
\hline$\geq$ Median & $72(18)$ & 19.0 & 22.2 & \\
\hline Sex & & & & .643 \\
\hline Male & $117(34)$ & 19.0 & 22.6 & \\
\hline Female & $26(9)$ & 19.3 & 33.5 & \\
\hline Siewert type & & & & .401 \\
\hline Type I & $20(5)$ & 15.5 & 18.7 & \\
\hline Type II & $62(22)$ & 23.5 & 27.1 & \\
\hline Type III & $61(16)$ & 17.4 & 24.5 & \\
\hline Lauren type & & & & $<.001$ \\
\hline Intestinal & $102(36)$ & 23.5 & 30.4 & \\
\hline Nonintestinal & $41(7)$ & 12.9 & 10.4 & \\
\hline $\begin{array}{l}\text { Depth of invasion } \\
\text { (pT) }\end{array}$ & & & & $<.001$ \\
\hline pT2 & $62(26)$ & 36.3 & 35.2 & \\
\hline pT3 & $69(15)$ & 16.9 & 18.4 & \\
\hline pT4 & $12(2)$ & 7.4 & 0 & \\
\hline No. of positive nodes & & & & $<.001$ \\
\hline 0 & $32(20)$ & - & 53.9 & \\
\hline $1-6$ & $53(15)$ & 20.0 & 25.9 & \\
\hline$>6$ & $50(8)$ & 12.7 & 3.9 & \\
\hline $\begin{array}{c}\text { Level of positive } \\
\text { nodes }\end{array}$ & & & & $<.001$ \\
\hline pNO & $32(20)$ & - & 53.9 & \\
\hline First tier & $43(13)$ & 19.5 & 28.7 & \\
\hline Non-first tier & $68(10)$ & 14.7 & 5.5 & \\
\hline R category & & & & $<.001$ \\
\hline Ro & $129(43)$ & 22.3 & 27.8 & \\
\hline $\mathrm{R} 1$ & $14(0)$ & 6.9 & 0 & \\
\hline
\end{tabular}

JGCA, Japanese Gastric Cancer Association. *For pN0, median survival was beyond the observation period. †Five-year survival was calculated by using the Kaplan-Meier method. $¥ P$ value was computed by using the log-rank test.

involvement in 104 cases of type I cancers and a percentage of about $5 \%$ in 48 cases of type II tumors. On the other hand, the incidence of metastases to supradiaphragmatic (station 111) and lower mediastinal nodes are comparable (station 112), with data reported by Dresner and colleagues ${ }^{8}$ and Yuasa and associates. ${ }^{32}$ As reported in Table 2, only about one third of patients with Siewert type III tumors had mediastinal lymph nodes retrieved. This is due to the fact that two thirds of tumors reached the GEJ with a marginal invasion of the esophagus, and hence the involvement of mediastinal stations was considered unusual. Certainly, this statement cannot be regarded as definitive without a complete clearing of chest nodes in each case.

Subcarinal node (station 107) involvement was identified in 5\% of type I and $1.6 \%$ of type II tumors. Nigro and coworkers ${ }^{9}$ reported slightly higher percentages in $8(13 \%)$ cases of distal esophageal and in $36(8.3 \%)$ cases of GEJ adenocarcinoma in patients who underwent en bloc esophagectomy for tumors with transmural growth. Dresner and colleagues ${ }^{8}$ in the above-mentioned study, recorded a percentage of about $10 \%$ in type I and $0 \%$ in type II cancers.

Taking into account abdominal lymphatic spread, lesser curvature (station 3) and right paracardial nodes (station 1) were the most frequently involved. Less common was the involvement of stations along the left side of the stomach (stations 2, 4, and 6).

Altogether, the 3 Siewert types often spread to second-tier abdominal nodes. Above all, left gastric artery nodes (station 7) were affected in $20 \%$ of type I (14\%-60\%), $30.6 \%$ of type II $(18 \%-65 \%)$, and $18 \%$ in type III $(10 \%-42 \%)$ tumors. ${ }^{8,9,31-33}$ Likewise, the percentage of metastases to the common hepatic artery (station 8) and celiac trunk nodes (station 9) cannot be considered negligible (10\%-17.7\%).

Interestingly enough, para-aortic node metastases (station 16) were an extremely common event when considering type III cancers. Nodal diffusion to para-aortic stations was present in $13.1 \%$ of all resected patients and in the 29.6\% of patients who underwent D3 lymphadenectomy (data not shown). Consistently, a rate of $30 \%$ was reported by Hsu and associates. ${ }^{34}$

Considering the data reported here, it should be taken into account that in this clinical study, the extent of lymph node dissection was tailored according to tumor location, and lymph node dissection differed in the 3 Siewert types. As a consequence, an underestimation of the real frequency of involvement of some nodal stations is possible. As a fact, the abovementioned data prove the regular involvement of second-tier (and third-tier) nodes in GEJ adenocarcinoma and support the use of extended lymphadenectomy to achieve complete removal of the tumor. Transthoracic subtotal esophagectomy with standard 2-field lymphadenectomy is regarded as the treatment of choice for type I and type II tumors with significant esophageal involvement, ${ }^{35}$ even though some authors, taking into account the possibility of metastases to upper mediastinal $^{36}$ and cervical ${ }^{19,37}$ nodes, advocate the use of more extensive lymph node dissection (extended 2-field and 3-field lymphadenectomy). In view of the high rate of second-tier abdominal node involvement, the use of D2 lymphadenectomy seems to be advisable in type I and II tumors, whereas a lymph node dissection extended to para-aortic nodes (D3 lymphadenectomy) would be justified in type III and type II tumors with major gastric involvement. ${ }^{34,38}$

Conversely, one could argue that the poor long-term results reported in the present, as in previous experiences after adequate lymph node clearing, ${ }^{9,18,30,39}$ do not justify the use of an extended lymphadenectomy. ${ }^{40}$ As a matter of fact, in our study little chance of survival was observed for patients with involvement of second-tier (and third-tier) lymph nodes, ${ }^{5,18,30}$ as well as for patients with more than 6 metastatic nodes, which confirms the findings reported by 
TABLE 5. Survival according to the presence of nodal metastasis in each JGCA nodal station for the 111 patients with $\mathrm{pN}^{+}$ disease

\begin{tabular}{llccc}
\hline & Lymph node station (JGCA) & No. of patients (no. alive) & Median survival & 5-y survival $^{*}$ \\
\hline 1 & Right paracardial & $55(11)$ & 17.1 & 11.7 \\
2 & Left paracardial & $35(8)$ & 17.1 & 0 \\
3 & Lesser curvature & $87(16)$ & 14.1 & 15.5 \\
$4 \mathrm{~s}$ & Greater curvature & $7(0)$ & 14.1 & 14.3 \\
$4 \mathrm{~d}$ & Right gastroepiploic artery & $10(1)$ & 13.4 & 0 \\
5,6 & Suprapyloric/infrapyloric & $7(0)$ & 5.0 & 0 \\
7 & Left gastric artery & $34(7)$ & 13.6 & 6.4 \\
$8,9,11$ & Celiac trunk arteries & $34(4)$ & 13.6 & 0 \\
16 & Para-aortic & $10(0)$ & 7.2 & 0 \\
107,108 & Subcarinal/paraesophageal middle third & $3(1)$ & 13.8 & $33.3 \dagger$ \\
110 & Paraesophageal lower third & $15(3)$ & 13.8 & 0 \\
111,112 & Supradiaphragmatic/posterior & $14(3)$ & 14.2 & 0
\end{tabular}

JGCA, Japanese Gastric Cancer Association. *Five-year survival was calculated by using the Kaplan-Meier method. †Survival was computed at 25.8 months.

other authors. ${ }^{8,36,41}$ However, because this is a retrospective study with no control group, the role of extended lymph node dissection in improving survival cannot be assessed. In light of these results, we can affirm that the high frequency of nodal metastases and the related unfavorable long-term outcome achieved by means of surgical intervention alone are indicative of the need for aggressive multimodal treatment along with surgical intervention to improve the survival possibilities of these patients. ${ }^{14,42}$ Accordingly, some attention should be provided to thoracoscopy or laparoscopy as staging tools useful in guiding the choice of treatment. ${ }^{43}$

\section{References}

1. Devessa SS, Blot WJ, Fraumeni JF Jr. Changing patterns in the incidence of esophageal and gastric carcinoma in the United States. Cancer. 1998;83:2049-53.

2. Dolan K, Sutton R, Walker SJ, et al. New classification of oesophageal and gastric carcinomas derived from changing patterns in epidemiology. Br J Cancer. 1999;80:834-42.

3. de Manzoni G, Pedrazzani C, Pasini F, et al. Results of surgical treatment of adenocarcinoma of the gastric cardia. Ann Thorac Surg. 2002;73:1035-40.

4. Siewert JR, Feith M, Werner M, et al. Adenocarcinoma of the esophagogastric junction. Results of surgical therapy based on anatomical/ topographic classification in 1,002 consecutive patients. Ann Surg. 2000;232:353-61.

5. Kodera Y, Yamamura Y, Shimizu Y, et al. Adenocarcinoma of the gastroesophageal junction in Japan: relevance of Siewert's classification applied to 177 cases resected at a single Institution. J Am Coll Surg. 1999;189:594-601.

6. de Manzoni G, Pedrazzani C, Verlato G, et al. Comparison of old and new TNM classification systems for nodal staging of adenocarcinoma of the gastro-oesophageal junction. Br J Surg. 2004;91:296-303.

7. Collard JM. Exclusive radical surgery for esophageal adenocarcinoma. Cancer. 2001;91:1098-104.

8. Dresner SM, Lamb PJ, Bennett MK, et al. The pattern of metastatic lymph node dissemination from adenocarcinoma of the esophagogastric junction. Surgery. 2001;129:103-9.

9. Nigro JJ, DeMeester SR, Hagen JA, et al. Node status in transmural esophageal adenocarcinoma and outcome after en bloc esophagectomy. J Thorac Cardiovasc Surg. 1999;117:960-8.
10. Di Leo A, Marrelli D, Roviello F, et al. Lymph nodes involvement in gastric cancer for different tumor's site and T stage. Italian Research Group for Gastric Cancer (IRGGC) experience. J Gastrointest Surg. 2007. In press.

11. Roviello F, Marrelli D, Morgagni P, et al. Survival benefit of extended D2 lymphadenectomy in gastric cancer with involvement of second level lymph nodes: a longitudinal multicenter study. Ann Surg Oncol. 2002;9:894-900.

12. Kodera Y, Sasako M, Yamamoto S, et al. Identification of risk factors for the development of complications following extended and superextended lymphadenectomies for gastric cancer. Br J Surg. 2005;92: 1103-9.

13. Siewert JR, Stein HJ. Classification of adenocarcinoma of the oesophagogastric-junction. Br J Surg. 1998;85:1457-9.

14. Pasini F, de Manzoni G, Pedrazzani C, et al. High pathological response rate in locally advanced esophageal cancer after neoadjuvant combined modality therapy: dose finding of a weekly chemotherapy schedule with protracted venous infusion of 5-fluorouracil and dose escalation of cisplatin, docetaxel and concurrent radiotherapy. Ann Oncol. 2005; 16:1133-9.

15. Japanese Gastric Cancer Association (JGCA). The new Japanese Classification of Gastric Carcinoma. 2nd English ed. Gastric Cancer. 1998:1:1-15

16. Sobin LH, Wittekind C, International Union Against Cancer (UICC): TNM classification of malignant tumours. 5th ed. New York: John Wiley \& Sons; 1997.

17. de Manzoni G, Verlato G, Guglielmi A, et al. Prognostic significance of lymph node dissection in gastric cancer. Br J Surg. 1996;83:1604-7.

18. Lagarde SM, Cense HA, Hulscher JB, et al. Prospective analysis of patients with adenocarcinoma of the gastric cardia and lymph node metastasis in the proximal field of the chest. Br J Surg. 2005;92: 1404-8.

19. Lerut T, Nafteux P, Moons J, et al. Three-field lymphadenectomy for carcinoma of the esophagus and gastroesophageal junction in $174 \mathrm{R} 0$ resections: impact on staging, disease-free survival, and outcome: a plea for adaptation of TNM classification in upper-half esophageal carcinoma. Ann Surg. 2004;240:962-72.

20. Collard JM, Otte JB, Fiasse R, et al. Skeletonizing en bloc esophagectomy for cancer. Ann Surg. 2001;234:25-32.

21. Ito H, Clancy TE, Osteen RT, et al. Adenocarcinoma of the gastric cardia: what is the optimal surgical approach? J Am Coll Surg. 2004; 199:880-6.

22. Hansson LE, Sparen P, Nyren O. Survival in stomach cancer is improving: results of a nationwide population-based Swedish study. Ann Surg. 1999;230:162-9. 
23. Mariette C, Castel B, Toursel H, et al. Surgical management of and long-term survival after adenocarcinoma of the cardia. $\mathrm{Br} J$ Surg. 2002;89:1156-63.

24. de Manzoni, Pedrazzani C, Pasini F, et al. Pattern of recurrence after surgery in adenocarcinoma of the gastro-oesophageal junction. Eur J Surg Oncol. 2003;29:506-10.

25. Lerut T, Coosemans W, Decker G, et al. Extended surgery for cancer of the esophagus and gastroesophageal junction. J Surg Res. 2004;117:58-63.

26. Hulscher JB, van Sandick JW, de Boer AG, et al. Extended transthoracic resection compared with limited transhiatal resection for adenocarcinoma of the esophagus. N Engl J Med. 2002;347:1662-9.

27. Bonekamp JJ, Hermans M, Sasako M, et al. Extended lymph node dissection for gastric cancer. N Engl J Med. 1999;340:908-914.

28. Cuschieri A, Weeden S, Fielding J, et al. Patient survival after D1 and D2 resections for gastric cancer: long-term results of the MRC randomized surgical trial. Surgical Co-operative Group. $\mathrm{Br} J$ Cancer. 1999;79:1522-30

29. Aikou T, Shimazu H. Difference in main lymphatic pathways from the lower esophagus and gastric cardia. Jpn J Surg. 1989;19:290-5.

30. Steup WH, De Leyn P, Deneffe G, et al. Tumors of the esophagogastric junction. Long-term survival in relation to the pattern of lymph node metastasis and a critical analysis of the accuracy or inaccuracy of pTNM classification. J Thorac Cardiovasc Surg. 1996;111:85-94.

31. de Manzoni G, Morgagni P, Roviello F, et al. Nodal abdominal spread in adenocarcinoma of the cardia. Results of a multicenter prospective study. Gastric Cancer. 1998;1:146-51.

32. Yuasa N, Miyake H, Yamada T, et al. Clinicopathologic comparison of Siewert type II and III adenocarcinomas of the gastroesophageal junction. World J Surg. 2006;30:364-71.

33. Wijnhoven BPL, Siersema PD, Hop WCJ, et al. Adenocarcinomas of the distal oesophagus and gastric cardia are one clinical entity. $\mathrm{Br} \mathrm{J}$ Surg. 1999;86:529-35.
34. Hsu CP, Wu CC, Chen CY, et al. Clinical experience in radical lymphadenectomy for adenocarcinoma of the gastric cardia. $J$ Thorac Cardiovasc Surg. 1997;114:544-51.

35. Fumagalli U, Akiyama H, DeMeester TR. Resective surgery for cancer of the thoracic esophagus: results of a consensus conference held at the VIth World congress of the International Society for Diseases of the Esophagus. Dis Esophagus. 1996;9:30-8.

36. D'Journo XB, Doddoli C, Michelet P, et al. Transthoracic esophagectomy for adenocarcinoma of the oesophagus: standard versus extended two-field mediastinal lymphadenectomy? Eur J Thorac Cardiovasc Surg. 2005;27:697-704.

37. Altorki N, Kent M, Ferrara C, et al. Three-field lymph node dissection for squamous cell and adenocarcinoma of the esophagus. Ann Surg. 2002;236:177-83.

38. de Manzoni G, Pedrazzani C, Di Leo A, et al. Metastases to the para-aortic lymph nodes in adenocarcinoma of the cardia. Eur J Surg. 2001;167:413-8.

39. Lerut T, Coosemans W, Decker G, et al. Surgical techniques. J Surg Oncol. 2005;92:218-29.

40. Lin J, Iannettoni MD. Transhiatal esophagectomy. Surg Clin North Am. 2005;85:593-610.

41. Wayman J, Bennett MK, Raimes SA, et al. The pattern of recurrence of adenocarcinoma of the oesophago-gastric junction. $\mathrm{Br} J$ Cancer. 2002;86:1223-9.

42. Keller SM, Ryan LM, Coia LR, et al. High dose chemoradiotherapy followed by esophagectomy for adenocarcinoma of the esophagus and gastroesophageal junction: results of a phase II study of the Eastern Cooperative Oncology Group. Cancer. 1998;83:1908-16.

43. Krasna MJ, Reed CE, Nedzwiecki D, et al. CALGB 9380: a prospective trial of feasibility of thoracoscopy/laparoscopy in staging esophageal cancer. Ann Thorac Surg. 2001;71:1073-9. 